\title{
ENCONTROS COM O OUTRO: EMPATIA E InTERsubJetividAde No PRIMEIRo ANo DE VIDA ${ }^{1}$
}

\author{
Vera Silvia Raad Bussab ${ }^{2}$, Maria Isabel Pedrosa ${ }^{3}$ e \\ Ana Maria Almeida Carvalho ${ }^{2}$ \\ Instituto de Psicologia - USP \\ Universidade Federal de Pernambuco - UFPE
}

\begin{abstract}
A observação de um episódio de cuidado entre duas crianças de menos de 18 meses de idade desencadeou uma reflexão sobre a ontogênese da empatia. Descreve-se o episódio e apontam-se questões teóricas que ele suscita a respeito de concepções sobre a criança e o processo de desenvolvimento, e sobre a ontogênese da comunicação e da vida cultural. A seguir, revê-se, desse ângulo, a literatura sobre desenvolvimento sócioafetivo e cognitivo no primeiro ano de vida, a partir das perspectivas psicoetológica e sócio-construtivista, com alguma ênfase na contribuição de Henri Wallon, focalizando três conceitos: intersubjetividade, empatia e imitação. Essa literatura retrata o neonato humano como um ser biologicamente organizado para a vida sócio-cultural, na qual está imerso desde o nascimento - ou até mesmo desde a concepção - por meio de sua pré-organização para o encontro com o outro e para a troca social, condições constitutivas de seu desenvolvimento individual.
\end{abstract}

Descritores: Empatia. Intersubjetividade. Imitação. Bebês.

Desenvolvimento humano.

1 Pesquisa apoiada pelo CNPq.

2 Docentes do Departamento de Psicologia Experimental do Instituto de Psicologia da Universidade de São Paulo. Endereço eletrônico: vsbussab@usp.br e amacarva@uol.com.br

3 Docente da Universidade Federal de Pernambuco - UFPE

Psicologia USP, 2007, 18(2), 99-133. 
Vera Silvia Raad Bussab, Maria Isabel Pedrosa e Ana Maria Almeida Carvalho

\section{Encontros com o outro: empatia e intersubjetividade no primeiro ano de vida.}

Berçário de um orfanato em uma cidade do nordeste brasileiro. A câmera focaliza um menino de 9 meses - vamos chamá-lo de Lucas - sentado no chão, próximo aos berços alinhados junto à parede. Ouve-se ao fundo um choro forte e persistente.

Lucas olha à sua volta, olha para o adulto que filma, põe-se de quatro e começa a engatinhar. A câmera o segue. Ele engatinha através do espaço vazio no centro da sala, na direção de uma criança que chora intensamente mas não está sendo focada na cena. Lucas pára, senta-se a mais ou menos um metro da criança (Mário, 13 meses), que parou de chorar mas continua debruçada no chão, apoiada nos joelhos e sacudindo os ombros e a cabeça de forma que esta toca repetidamente seus braços dobrados e apoiados no chão.

Lucas olha em torno, inclusive novamente para o adulto que filma. Engatinha aproximando-se mais de Mário, que agora está com o rosto voltado para ele e talvez o veja. Lucas estende o braço esquerdo e passa a mão, desajeitadamente, na cabeça de Mário; muda de posição e passa agora a mão direita, depois toca com essa mão, também desajeitadamente, as costas de Mário, duas ou três vezes seguidas, como quem faz um afago. Mário pára de sacudir o corpo, ergue a cabeça e olha para Lucas.

Lucas olha para ele, olha em volta, senta-se, põe-se de quatro e se afasta engatinhando. Mário, ainda debruçado, olha fixamente para ele; Lucas se afasta, senta-se e olha na direção de Mário, depois se aproxima um pouco; este agora está de gatinhas e se aproxima de Lucas. Os dois estão próximos de um berço.

Mário se levanta, segurando uma barra do berço, e olha para Lucas. Lucas o imita, procurando segurar a barra do berço e se erguer. Estende o braço e dá dois tapinhas nas costas de Mário, depois encosta a mão em seu rosto. Mário olha para ele. Lucas, de joelhos, segura a barra do berço com as duas mãos. Mário segura uma barra mais acima, olha para Lucas; segura a barra inferior e passa as pernas sobre ela, colocando-se debaixo do berço; senta-se diante de Lucas, que continua segurando a barra, apoiado nos joelhos. Lucas olha para a barra superior, Mário a alcança com as duas mãos, olhando para Lucas; sua expressão sugere um sorriso. Lucas estende o braço, mas não consegue agarrar a barra superior. Mário, apoiado nos joelhos, olha para Lucas e bate palmas, aproximando seu rosto do de Lucas. As duas crianças alternam movimentos de erguer e abaixar e balançar o corpo segurando a barra. Uma terceira criança se aproxima e entra na brincadeira. Lucas olha para ela, Mário sai de debaixo do berço, olha para a câmera e se afasta. Lucas volta a olhar para ele. (Figura 1). 


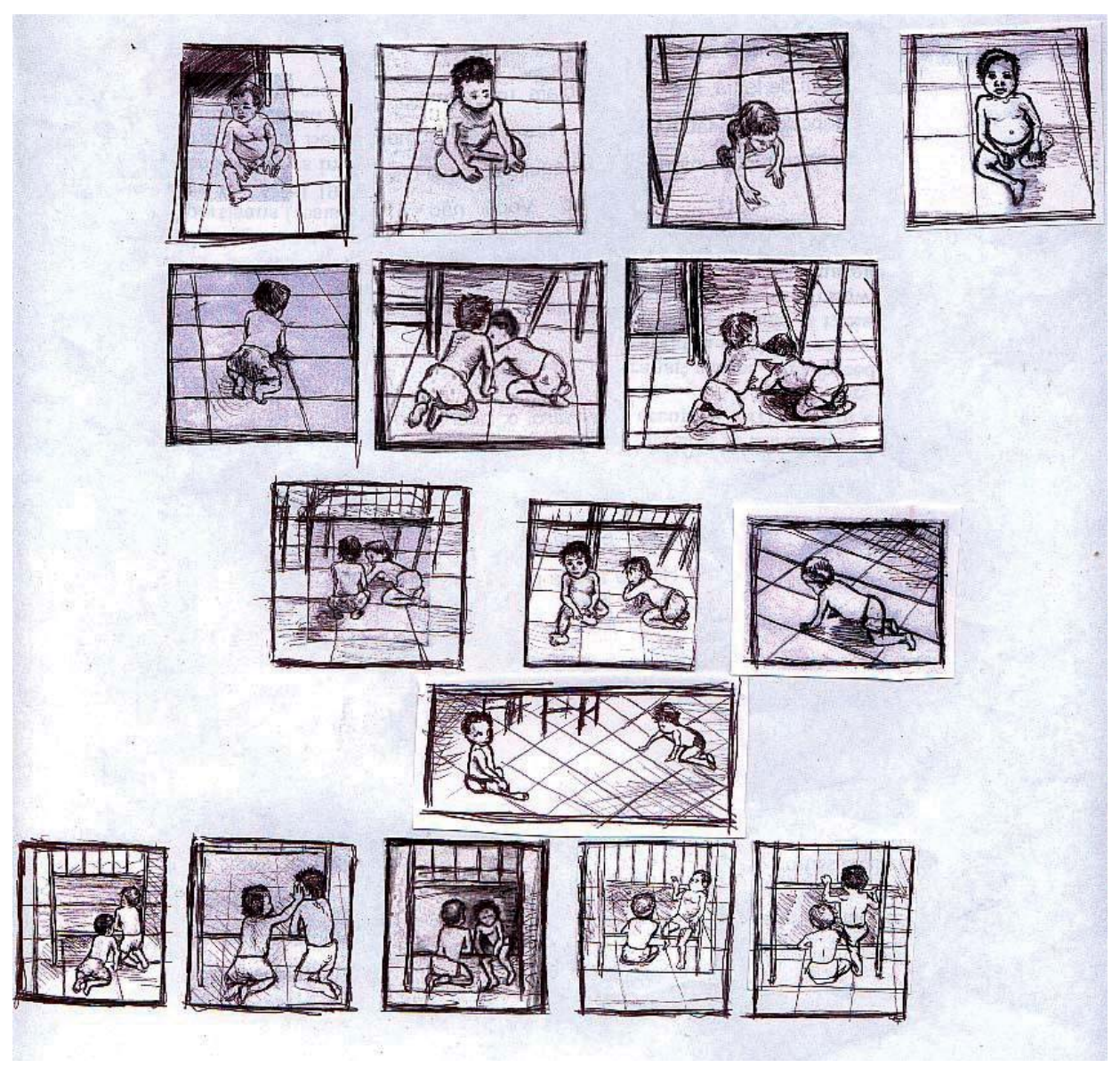

Figura 1: Representação do episódio. Ilustração a partir de foto/vídeo, por David A. L. Carvalho.

Essa observação casual, registrada acidentalmente em vídeo, levanta questões teóricas intrigantes, com implicações potencialmente importantes em termos de concepções sobre a criança, o desenvolvimento e a natureza da sociabilidade humana. É praticamente impossível evitar a interpretação de que Lucas de alguma maneira percebe o estado de desconforto de Mário e age de uma forma que, acidentalmente ou não, o minimiza. Isso não implica supor em Lucas uma intencionalidade no sentido estrito, conscientizada; implica, no 
entanto, um nível de percepção interpessoal para o qual a teorização clássica da psicologia do desenvolvimento até há pouco tempo reservava muito pouco espaço no que concerne aos estudos dessa idade tão precoce. Prevalecia - e ainda prevalece em muitas teorias, apesar de grandes reformulações nas últimas décadas - a noção de que o ser humano nasce enclausurado em si mesmo, vazio do mundo e sem nenhuma - ou com muito pouca - preparação para vivenciá-lo; o mundo o constituiria de forma mais ou menos arbitrária, socializando-o de acordo com parâmetros e valores históricos e culturais variáveis - entre os quais inclui-se até, em maior ou menor grau, a empatia em relação ao outro, que muitos ainda vêem como uma conquista da "socialização" contra o "egoísmo" ou autocentração "naturais" ou biológicos. À luz de observações como a descrita acima e da literatura mais recente, parece razoável perguntar acerca da natureza da compreensão de crianças sobre sentimentos, intenções e ações dos outros, sobre regras sociais ou relacionamentos entre os que compartilham o seu mundo social (cf. Carvalho \& Pedrosa, 1993; Dunn, 1988). Em última análise, perguntamos sobre o que é "ser social" na forma especificamente humana desse modo de ser.

A reflexão sobre essas questões motivou esta revisão crítica da literatura, na qual percorremos: o caminho teórico e empírico que levou à revolução recente (e ainda em andamento) nas concepções sobre o bebê, e a seu reconhecimento como um ser biologicamente social; a concepção walloniana sobre o papel do outro na construção do eu, e da emoção, do corpo e do contágio emocional na comunicação no início da vida; o fenômeno da empatia; e ensaios de integração dessas teorizações e evidências através do conceito de intersubjetividade - de forma a tentar extrair suas implicações para a pergunta: como entender o que aconteceu entre Lucas e Mário?

\section{A agenda do bebê}

Desde os primeiros instantes depois do nascimento, os bebês se revelam protagonistas de um enredo psicológico especial, o enredo do encontro com o outro. As descrições minuciosas do recém-nascido têm nos emocionado ao demonstrar o que, de algum modo, sempre soubemos: chegamos ao mundo com um encontro marcado. 
Nas últimas décadas, observações sistemáticas produziram uma verdadeira revolução nos conhecimentos sobre o recém-nascido. Apesar do enorme interesse que sempre tivemos, não tínhamos tido ainda tanto acesso ao mundo psicológico dos bebês. É possível até que nosso envolvimento excessivo tenha nos impedido de perceber o grau de reciprocidade do interesse e a magnitude da participação ativa dos bebês. As descobertas mais recentes revelaram uma nova criança e, de quebra, amadureceram nossos conhecimentos; demonstraram, acima de tudo, a importância da investigação sistemática e da atitude de aprendiz do pesquisador. Não deixa de ser emocionante a idéia de a Psicologia estar se desenvolvendo ao aprender com os bebês sobre quem somos nós.

Os estudos de desenvolvimento inicial têm sido decisivos. Desde o nascimento apresentamos inclinações para a regulação social, referenciamento no outro, compartilhamentos e formação de vínculos afetivos. Dizer que as crianças nascem "prontas para aprender" ainda é muito pouco, diante da complexidade do processo de assimilação ativa do mundo social e afetivamente referido à sua volta: crianças nascem prontas para apreender e compartilhar (Bussab, 2003).

Os bebês respondem seletivamente a estímulos humanos típicos, como tem ficado claro desde as demonstrações clássicas da preferência por faces em comparação com outros estímulos de complexidade equivalente (Fantz, 1963). A capacidade precoce de reconhecimento individual também é sugestiva da importância da vinculação individualizada. Só para se ter uma idéia, na primeira semana de vida os bebês já são capazes de identificar e preferir a mãe a estranhos, pelo odor (Schaal et al., 1980), pela voz (MacFarlane, 1975) e pela face (Field, Cohen, Garcia, \& Greenberg, 1984).

O contato de olhar fornece uma pista importante para o estudioso e parece ser para a criança um ponto de partida fundamental. Logo depois do nascimento, pode ser observada uma busca imediata do olhar, que é seguida por tranqüilização, focalização da atenção e por trocas interacionais ajustadas (como em Csillag, 1997; Klaus \& Kennel, 1992; Murray \& Andrews, 2000) .

Não menos significativa é a capacidade dos bebês de reagir diferencialmente aos sinais interacionais do adulto. O contato de olhar e a fala afetuosa despertam sorrisos (Otta, 1994), bem como aumentam o envolvimento interacional do bebê, que abre mais os olhos e coloca-se em estado de alerta; mesmo 
os recém-nascidos pré-termo já apresentam esse padrão básico de reação para o contato face a face e para a fala maternal (Eckerman, Oehler, Medvin \& Hannan, 1994). O colo aquieta e organiza (Klaus \& Kennel, 1992). A cadência da fala sincroniza o ritmo comportamental do bebê, que se movimenta embalado pela musicalidade da vocalização ouvida, conforme se pode verificar pela micro-análise dos padrões (Condon \& Sander, 1974). Reações de agrado e de desagrado de recém-nascidos a estímulos nociceptivos, e a estímulos olfativos e gustativos, evidenciam sintonia complexa com o ambiente, excluindo a possibilidade de interpretação em termos de reações reflexas (Bergamasco, 1997). Seguindo as pistas fornecidas pelas reações de prazer e desprazer, podemos descobrir a importância das interações sociais e da regulação recíproca desde o início do desenvolvimento; as emoções básicas de alegria, interesse, tristeza e raiva aparecem de modo típico e universal, associadas respectivamente à manutenção, às quebras e aos excessos interacionais.

A busca de referenciamento social também é notável: em qualquer tipo de situação nova, o bebê procura informações no outro, de preferência nas pessoas conhecidas, às quais esteja ligado afetivamente. Um bebê de dois meses reage a um estranho desviando o olhar, inquietando-se e olhando nos olhos da mãe (Mizukami, Kobayashi, Ishii \& Iwata, 1990), como se estivesse em busca de informações. A utilização da mãe como uma base de segurança tranqüiliza, informa e permite, a partir daí, uma exploração mais direta do estranho pela própria criança, caso a reação da mãe seja amistosa.

Uma descoberta aparentemente pequena, mas emocionante e perturbadora, nasceu de estudos de laboratório: recém-nascidos são capazes de imitar expressões faciais, sem espelho e sem ensaio! As demonstrações dessa capacidade vêm se acumulando a partir de Meltzoff e Moore (1977, 1983, 1994, 1998). O bebê é capaz de igualar expressões faciais que vê, desde a primeira hora de vida (Kugiumutzakis, 1998), o que prova que ele é capaz não só de enxergar, como de agir realizando integração sensório-motora inesperada até recentemente pelas teorias de desenvolvimento vigentes. Por causa da expectativa gerada por essas teorias, pesou sobre esse fenômeno polêmica e o ônus de demonstrações sucessivas, sob acusações metodológicas: não estaríamos vendo imitação numa sucessão de caretas sem sentido? Todavia, as demonstrações metodologicamente rigorosas foram reiteradas de maneira inequívoca 
(Bussab, 2003). É interessante resgatar em Darwin (1872/ 1995) menção ao fato: ao observar como seu filho de seis meses imitou a expressão de tristeza da babá, ele especulou sobre a existência de uma base inata para essa imitação. Um século depois, a confirmação dessa suposição recolocou o papel da imitação no desenvolvimento, contrapondo-se às idéias então preponderantes do "autismo normal" ou da atitude egocêntrica do recém-nascido, como em Baldwin, Freud e Piaget (Bråten, 1998).

O compartilhamento emocional merece destaque. Em alguns trabalhos, as fotos de bebês imitando expressões de emoção são sugestivas de contágio emocional, como, por exemplo, no caso das imagens documentadas por Field, Woodson, Greenberg e Cohen (1982). Ao olhar para elas, não temos a impressão de uma caricatura periférica e, sim, de uma expressão genuína, possivelmente por causa do complexo conjunto de sinais exibidos, envolvendo desde brilho do olhar e dilatação de pupila até tônus muscular geral e outros sinais. Esses indicadores de contágio emocional têm sido entendidos como sugestivos da presença precoce da capacidade empática, definida como uma resposta vicária à emoção do outro, englobando componentes motivacionais, cognitivos e afetivos (Santana, Otta, \& Bastos, 1993), e que tem sido considerada como mediadora de comportamentos de ajuda ao outro. $\mathrm{O}$ choro de recém-nascidos em resposta ao choro de outro bebê pode ser visto como um precursor primitivo da ativação empática (Hoffmann, 1981). Desde muito cedo a criança pode apresentar, em relação a outras, padrões que mimetizam o comportamento típico do adulto de cuidado e de proteção dirigido a crianças pequenas, incluindo cuidados físicos, ajudar, contato afetuoso e entreter (Lordelo \& Carvalho, 1989), refletindo-se ainda em ajustes como de nivelamento postural e de modulação vocal. Embora a ajuda apareça tipicamente durante o segundo ano, sua presença no primeiro ano é marcante, reveladora e parece ser universal. Eibl-Eibesfeldt (1989) mostra uma seqüência de fotos de uma menina Yanomani de cerca de um ano, que ajuda outro bebê que está chorando, oferecendo o seio de sua própria mãe. São também tocantes as imagens de bebês, de várias culturas, alimentando boca a boca crianças ainda menores, do mesmo modo que suas mães fazem com eles próprios. De forma análoga, no episódio descrito no início deste texto, uma criança de menos de um ano, ouvindo um choro, engatinha pela sala, chega perto da criança que chora e a acaricia.

4 A primeira data refere-se à publicação original, e a segunda, à edição consultada. 
Nascemos com uma emocionante capacidade de troca, ajuste e compartilhamento. Ao chamarmos essa capacidade de imitação neonatal estamos salientando apenas um de seus aspectos e, possivelmente, ofuscando seu sentido mais fundamental, que é o do próprio compartilhamento: estar junto, sentirse como, conjugar a atenção, colocar-se no mesmo contexto psicológico.

Essa é uma característica fundamental que nos acompanha por toda a vida. Tendemos a espelhar a expressão emocional uns dos outros, quando envolvidos numa interação, mesmo sem nos dar conta do que está acontecendo. É como se compartilhássemos as emoções sentidas, os esforços e tudo o mais. Alguns episódios isolados podem facilitar nossa auto-percepção: por exemplo, quem já teve a oportunidade de dar de comer a uma criança pequena às colheradas pode ter se flagrado abrindo a boca e engolindo no vazio.

É mais do que provável, ainda, que estejamos destacando a imitação facial apenas porque está na cara, dito popular que reflete o conhecimento bem difundido do poder de expressividade da face. Ainda assim, o corpo todo parece participar da interação social e da regulação recíproca através de movimentos e de posturas. Sabe-se que, além dos igualamentos faciais, posturais e dos demais movimentos do corpo, ocorrem também imitações de expressões vocais. Crianças igualam vocalizações da mãe em uníssono e no mesmo tom, ainda que uma escala acima. Micro-análises dos padrões interacionais também mostraram ajustes de ritmos. A identificação da existência de sincronia interacional em bebês, revelada pela conjugação harmoniosa dos movimentos dos bebês com o padrão rítmico da fala do seu interlocutor (Condon \& Sander, 1974), mostra a regulação interacional como uma dança sincronizada decorrente de um engajamento básico geral. Quanto maior o envolvimento, maior a simultaneidade. Tudo indica que fenômenos globais também estejam subjacentes às chamadas imitações neo-natais, envolvendo não apenas vários níveis sensoriais e motores, mas também complexos processos de integração. Convém notar que, apesar, de vez por outra, estarmos nos fixando em determinados aspectos da interação, estamos nos referindo a processos básicos mais gerais.

Uma foto documentada por Eibl-Eibesfeldt (1989) mostra uma menina de dois meses sorrindo para a mãe, que fala carinhosamente com ela. Apesar de cega de nascença, a menina exibia um sorriso pleno, fixava o olhar 
na direção da fonte de som e apresentava, no tônus muscular e na posição das mãos, indicações de engajamento interacional pleno. É claro que prejuízos sensoriais podem afetar as trocas interacionais. Entretanto, o exemplo ilustra a importância do conjunto: o compartilhamento se processa em vários níveis e através de pistas diversas.

Regulações recíprocas nas interações bebês-adultos, com sincronização dos ritmos interacionais e sensibilidade aos sinais mútuos, vêm sendo sucessivamente desvendadas. A igualação de expressão do bebê pela mãe aumenta o envolvimento interacional do bebê (Field, Guy \& Umbei, 1985), o que mostra que ele reage a características complexas e sutis da situação de interação.

As demonstrações das capacidades precoces de recém-nascidos para o engajamento interpessoal apontam uma pré-adaptação a um ambiente de envolvimento interpessoal consistente, o que não tem passado despercebido a muitos de nós (como Murray, 1998). A natureza humana parece ter ajustado o indivíduo para se desenvolver em função da rede social e afetiva na qual ele está imerso. Isso cria um interesse especial no acompanhamento ontogenético da expressão das características humanas e na compreensão das especificidades do contexto sócio-afetivo do ambiente de desenvolvimento.

Pode-se dizer que as demonstrações das últimas décadas puseram fim a qualquer dúvida e confirmaram posições anteriores compatíveis com a primazia do interpessoal na ontogênese do pensamento e da linguagem (como Vygotsky, 1934/1986). Desdobramentos de conceitos propostos por Vygotsky têm sido aplicados à interação inicial mãe-bebê, como no estudo de gênese de "zonas de construção", que envolvem a apropriação e a negociação de significações (Ribas \& Seidl de Moura, 1998; Seidl de Moura \& Ribas, 2000). A aproximação entre aspectos sociais, afetivos e cognitivos tem sido promovida, com ênfase na compreensão do desenvolvimento cultural. As interações mãe-bebê, ou mais genericamente cuidador-bebê, que têm sido vistas como produto de uma série de transformações resultantes da evolução da espécie e da ontogênese dos indivíduos, são entendidas como constituindo a via inicial de inserção do bebê na cultura, criando o nicho em que se regulam, em termos de limite e de facilitação, as características peculiares de cada criança, assim como as características que ela compartilha com os demais membros do seu 
grupo e da sua espécie (Seidl de Moura, 1999); o papel de parceiros de idade nessa inserção é cada vez mais reconhecido a partir da década de 70 do século XX (Camaioni, 1980; Carvalho \& Beraldo, 1989; Carvalho, Magalhães, Pontes, \& Bichara, 2003). A convergência de setores diversos de pesquisa para a consideração do contexto interpessoal em que se dá o desenvolvimento serve para reiterar a sua importância e confirmar seu sentido: o recorte fundamental do mundo pelo bebê - o núcleo de seu "ambiente natural" - é o outro; em sua agenda, o item principal é o encontro. É com o outro, e através dele, que se constitui o eu.

\section{Diferenciação eu-outro}

Um dos processos em curso no período inicial de vida da criança é a constituição do eu-outro, que ocorre no envolvimento dos participantes em muitos tipos de relações possíveis no seu ambiente interacional. As manifestações afetivas participam de modo significativo nesse processo, pois, desde a mais tenra idade, a criança é sensível a tais manifestações: ela expressa, através de recursos fisionômicos, gestuais, posturais e rítmicos, seus estados de sensibilidade afetiva, e é capaz de percebê-los nos outros que lidam com ela (cf., por ex., Carvalho, 1988, 1989; Pedrosa, 1996; Trevarthen, 1984; Wallon, 1934/1971a).

Wallon (1934/1971b), ao discutir os primórdios do processo de diferenciação eu-outro, coloca que, ao assistir a uma cena diretamente, a criança pequena se impregna ou se contagia com disposições afetivas dos personagens. Tais disposições afetivas não se justificam nela própria, porque o aspecto associado àquela disposição do outro não a atingiu a não ser por contágio, e isso instiga um sentimento de uma certa diferença entre ela e o outro. Essa diferenciação eu-outro é um estado de confusão parcial, tem avanços e retrocessos - como, de resto, ocorre ao longo de toda a vida humana.

A noção eu-outro é fundamental na experiência humana. Segundo Ades (1998, p. 123), "o eu é... um ponto de convergência e de integração para as características que me definem, a cor dos olhos, a altura, a formação profissional, o que estou pensando agora, o conjunto de minhas lembranças, etc.". 
Inspirando-se nas idéias de Chisholm ${ }^{5}$, Ades define o eu não como um somatório de experiências ou percepções que vão acontecendo no dia-a-dia do sujeito, mas como uma classe à qual pertencem essas experiências e percepções, ou seja, um conceito que se modifica a partir de novas informações que o sujeito adquire, seja por constatação direta - observações introspectivas ou observações de seus aspectos externos - seja através do outro - seu olhar ou sua opinião.

Como se constitui essa noção de eu/outro? Qual o seu ponto de partida? Segundo Wallon (1986) a criança, no início de sua vida, encontra-se num estado de fusão com os outros. Mas, através de um outro íntimo, inicia-se um processo de diferenciação. A sua explicação para esse processo é resumida por Zazzo (1978, p. 49) do seguinte modo: "entre o eu e os outros, a relação estabelece-se por intermédio do outro que cada um traz consigo. Esse outro é designado por Wallon também pelos termos de alter, de outro íntimo, de "socius".

Mas qual a origem desse outro se, de início, não existe um eu? Para Wallon (1986) esse estado corresponde a uma consciência nebulosa na qual se difundiriam as ações sensório-motoras de origem exógena e endógena. É nessa nebulosa que começa a se esboçar um núcleo de condensação, o eu, e também um satélite, o sub-eu, ou o outro. Este outro data de um período em que os outros ainda não existiam, mas é ele, suas próprias variações, que regulam as nossas relações com os outros, considerando as necessárias adaptações às circunstâncias normais de vida.

O socius é uma necessidade absoluta para a criança, pois ela é incapaz de sobreviver se suas reações não forem completadas, compensadas e interpretadas. Daí a concepção walloniana de que o homem é social geneticamente, biologicamente, pois, como Zazzo (1978) destaca, para Wallon "o substrato orgânico é o tecido material do psiquismo, ou mais precisamente... o psiquismo, a todos os seus níveis, procede ou emerge de processos biológicos" (p. 50).

A concepção de Wallon sobre os primórdios da constituição eu-outro é de difícil apreensão e, por vezes, parece contraditória com uma suposição central de sua teoria sobre a ontogênese do sujeito, que afirma ser a vida mental, o psiquismo, constituído com e a partir dos outros sujeitos em interação social,

5 Chisholm, R. M. (1969). On the observability of the self. Philosophy and Phenomenologial Research, 30, 7-21. 
logo um postulado não-inatista. Quando Wallon, tal como mencionado acima, fala de um outro que cada um traz consigo, o socius, que é pré-existente aos outros, e de um substrato orgânico como tecido material do psiquismo, tem-se a impressão de que essa explicação não se coaduna com sua concepção sóciointeracionista construtivista. Mas se pode constatar claramente em sua obra que suas explicações preservam uma continuidade entre o orgânico e o mental, ou seja, o biológico é substrato do psíquico, o ingrediente básico deste, que foi moldado evolucionariamente e cuja natureza se constitui num ambiente sócio-cultural.

A distinção íntima dos dois núcleos eu/outro vai ocorrendo a partir das experiências da criança e, de acordo com Wallon (Werebe \& Nadel-Brulfert, 1986, p. 18), é condição inicial "a integração de impressões polissensoriais ligadas ao território orgânico".

Pesquisas recentes têm sugerido que a percepção e os movimentos do corpo são fontes de informações básicas do ser humano a respeito de si próprio. Como já mencionamos acima, Meltzoff e Moore (1977, 1983, 1998) mostraram que bebês recém-nascidos são capazes de imitar movimentos de abrir a boca ou de protrusão da língua feitos por um adulto diante deles. Tratase, portanto, de uma imitação de partes invisíveis do corpo do próprio bebê: ele ajusta o movimento de seu rosto, apenas sentindo a expressão produzida, a um movimento do rosto de outra pessoa, expressão que é vista por ele. Essa imitação, além de oferecer indício de consciência proprioceptiva, revela a existência de regras de correspondência intermodal, pois há um emparelhamento cinestésico-visual.

Ades (1998) comenta trabalhos de pesquisa a respeito do fenômeno chamado membros fantasmas, considerado como indício de um eu corporal em que a imagem do corpo e o esquema corporal parecem prefigurados no sistema nervoso.

A análise do processo de diferenciação eu-outro que transcorre ao longo dos primeiros anos de vida é enriquecida quando se explora esse aspecto do eu corporal. Observando-se uma criança diante do espelho, vê-se que, em torno dos dezoito meses, ela toca no seu rosto, passando a mão sobre uma mancha qualquer - como de batom, por exemplo - posta no seu rosto de modo disfarçado. Antes dessa idade, a criança não oferece dicas de que percebe a 
mancha, ou tenta tocar no rosto que vê no espelho, como se a imagem ali refletida não fosse a sua própria imagem.

O teste do espelho traz um ingrediente a mais para esta discussão. Segundo Ades (1998), quando a criança toca no seu rosto, gesto critério, ela estabelece uma correspondência entre a imagem visual nova (ela refletida no espelho) e aspectos de seu eu corporal. Essa correspondência é também de natureza intermodal: ver-se e sentir-se cinestesicamente, logo, um emparelhamento cinestésico-visual. Mas a técnica do espelho, por outro lado, propicia uma dissociação espacial, porque o movimento visto, imagem refletida no espelho, não acontece no mesmo lugar onde o movimento é sentido, ou seja, em si própria.

Duplicando a experiência da criança - o senso cinestésico-proprioceptivo correspondendo, agora, a uma imagem visual -, a técnica do espelho cria uma situação de observação com dois locus de experiências para a criança. Mesmo que correspondências intermodais sejam observadas na criança bem antes de seu encontro no espelho, a experiência de dissociação espacial complexifica o fenômeno, criando dois planos espaciais e atrasando o momento em que essa correspondência intermodal passa a ser observada através de seu indício empírico, o gesto critério.

Diferentemente de reconhecer um aspecto de seu corpo (como uma mancha de tinta em seu nariz, ou a fivela colocada em seu cabelo, sinais que a marcam ou objetos que lhe pertencem, aspectos parciais e externos do seu eu), a avaliação de estados afetivos do outro, decorrentes ou não de sua própria ação, pode revelar aspectos de identificação do eu-outro mais centrais ao sujeito, ou seja, disposições íntimas, intersubjetivas, apreendidas pelas múltiplas pistas de contexto, dentre as quais o comportamento do outro e o seu próprio, bem como a apreensão de como o outro significa a si próprio e à própria criança.

Entre o eu (o sujeito) e o outro, ao qual e do qual o eu está alternadamente fundido e diferenciado, ou no eu-outro, é como se existisse uma conexão primordial, um "estado contínuo de contato potencial". Os modos de apreensão e de compreensão desse entre vêm sendo explorados na literatura sob o conceito de intersubjetividade. 
Vera Silvia Raad Bussab, Maria Isabel Pedrosa e Ana Maria Almeida Carvalho

\section{Intersubjetividade}

Nas últimas décadas, o conceito de intersubjetividade tem aparecido, implícita ou explicitamente, como um denominador comum nos estudos do envolvimento interpessoal de crianças pequenas e da compreensão que as crianças têm dos pensamentos e sentimentos dos outros (Bråten, 1998). Diferentes significados têm sido atribuídos ao conceito, refletindo diferentes ênfases: em seus aspectos afetivo-emocionais, ou em aspectos cognitivos (Bussab, 2003).

Cada vez que o fenômeno é referido, merece um tratamento que salienta alguns de seus aspectos. Há quem diga que os recém-nascidos apresentam uma inteligência interpessoal efetiva, chamando a atenção para o fato de que as novas evidências são incompatíveis com a crença de uma consciência simpatética humana como meta mais ou menos remota de desenvolvimento e, inversamente, considerando a presença desse tipo de consciência na criança pequena como sugestiva da naturalidade do traço (Trevarthen, 1998).

Com atenção especial aos aspectos emocionais, o fenômeno tem sido entendido como de comunhão entre pessoas, que se ligam e se ajustam aos estados e expressões emotivas umas das outras. Trevarthen (1984) foi um dos primeiros a chamar a atenção para a precocidade da "intersubjetividade primária", uma ligação motivada sujeito-sujeito, que caracteriza a protoconversação no início do desenvolvimento.

Outros aspectos dos fenômenos ligados à regulação social devem ser considerados. Experimentos de perturbação têm demonstrado consequiências imediatas da quebra da intersubjetividade. Foram investigadas reações de bebês de 6 a 12 semanas a dois tipos de perturbações na interação da mãe com o filho (Murray, 1980; Murray \& Trevarthen, 1985): num tipo de interrupção natural, decorrente da chegada de alguém que requisita a atenção da mãe; ou durante uma interrupção forçada, em que a mãe recebe instrução para parar de interagir e ficar com a face neutra, olhando para a criança. Durante os períodos de interação normal, os bebês mantêm o olhar dirigido e fazem movimentos ativos do corpo como um todo, além de deslocamentos específicos da boca e da língua, que têm sido referidos como padrões pré-verbais. Na condição de interrupção natural, os bebês param de exibir esses movimentos dirigidos, mas não apresentam outros sinais de perturbação. Na situação de interrupção 
forçada, as crianças dão sinais de perturbação: no início, mantêm o olhar, franzem a testa e aumentam o balbucio, o que sugere um tipo de protesto inicial; depois, fazem caretas, exibem atividades deslocadas com as mãos, como de automanipulação, e evitam o contato com a mãe, desviando o olhar. As mães se sensibilizam à aparente tristeza e desconforto do bebê, de tal modo que se revelam particularmente solícitas e atenciosas quando liberadas da instrução do pesquisador. Esses experimentos, já clássicos, demonstram a sensibilidade, presente nos bebês e nos adultos, aos sinais interacionais recíprocos.

Os bebês são capazes de interagir de modo ajustado com suas mães, numa condição em que, através de monitores de vídeo, são apresentadas imagens ao vivo da mãe para a criança e vice-versa. Na reapresentação de uma sequiência interacional gravada dessa forma - portanto, desta feita, sem relação com o curso interacional em andamento -, os bebês mostram sinais de perturbação, como caretas, deslocamentos, desvios de olhar e olhadas intermitentes, dando mais a impressão de confusão do que de protesto. Na reapresentação da mesma gravação para as mães, como se fosse de uma interação ao vivo, as mães acham que há algo errado e que não estão conseguindo ir junto com o filho. Na situação ao vivo, as mães exibem fala maternal, simples, repetitiva, especialmente centrada na experiência da criança; na reapresentação, falas mais complexas, mais centradas na própria experiência e também mais diretivas, controladoras e críticas (Murray, 1998).

O ajuste interacional do parceiro produz manutenção de atenção e engajamento positivo no bebê (Stern, 1985), o que poderia ser generalizado para tarefas não sociais (Durnham, Durnham, Hurshman, \& Alexander, 1989). Processos atencionais e motivacionais relevantes para as operações cognitivas poderiam estar fortemente baseados nas experiências infantis de engajamento interpessoal. Os estudos de desenvolvimento de apego mostraram que a vinculação afetiva se desenvolve no contexto interacional e lúdico: são essenciais as trocas ajustadas em resposta aos sinais da criança, e não a satisfação de outras necessidades primárias (Bowlby, 1969/1984).

Em resumo, os bebês são notavelmente sensíveis à qualidade da interação de um parceiro adulto e parecem apreender o significado pessoal de diferentes formas de engajamento. Suas respostas às disrupções do comportamento materno parecem ser formas complementares de adaptação, que têm 
papel regulador - tanto na própria experiência, permitindo tentativas de obter a atenção do parceiro ou, no limite, mudança do foco de interesse e proteção de frustração, quanto na do parceiro, que tem oportunidade de perceber as necessidades da criança. $\mathrm{O}$ desenvolvimento subseqüiente, incluindo aspectos afetivos, emocionais e cognitivos, parece depender em parte de experiências de manutenção de atenção interacional nas trocas com o adulto cuidador.

Outros autores salientaram aspectos cognitivos da intersubjetividade, destacando a atenção convergente a objetos de referência, num domínio partilhado de conversação lingüística ou extralingüística. Em um contexto interacional desse tipo, com partilha de atenção e compartilhamento emocional, a palavra parece se encaixar como uma luva (Bussab, 2003). Numa situação em que um adulto e um bebê estão engajados numa interação, sincronizados no mesmo ritmo, contagiados pela mesma emoção e compartilhando o foco da atenção num mesmo evento, a emissão, por parte de um adulto, de uma palavra referente a tal evento se preenche de pronto com um conteúdo interacionalmente significativo, com um conteúdo vivido. Não é de estranhar que o papel dessa intersubjetividade venha sendo reconhecido como crucial no desenvolvimento da linguagem (Tomasello, 1988). Trata-se de uma intersubjetividade triangular (também chamada secundária - Lyra \& Souza, 2003), no sentido de envolver relações sujeito-objeto-sujeito, num mundo partilhado de referência e manipulação de objetos. Análises minuciosas da interação mãebebê têm referendado essa idéia. Oliva (2001), trabalhando em conjunto com Leme, partiu da pressuposição de que o compartilhamento do foco da atenção entre mães e bebês seria condição para construção de categorias fundamentais da linguagem e mostrou que ajustes funcionais da fala de mãe são percebidos pelos bebês, com possíveis conseqüências no desenvolvimento.

Ao reiterar as ligações entre intersubjetividade e aquisição da linguagem, não se está isolando o aspecto cognitivo. Ao contrário, pretende-se destacar que essa origem interacional, apoiada nos significados compartilhados, abrange o emocional e o afetivo de modo pleno.

O processo de intersubjetividade pode ser entendido como essencial à cultura ao prover as bases da compreensão compartilhada. A imersão da mente individual na coletividade cultural parece estar baseada na responsividade mútua necessária para criar uma comunidade de significados (Rommetveit, 
1998). Por sua vez, esses significados devem ser entendidos de modo amplo. Ponto importante é levantado por Goodman (1978, p. 8), ao assinalar que o "sentimento sem compreensão é cego e a compreensão sem sentimento é vazia". A atividade rudimentar do bebê não é nem cega nem vazia. A tomada de perspectiva afetiva se constitui num pré-requisito de como a criança apreende o significado e, é claro, não fica restrita à infância. Aliás, constitui-se na essência do viver humano, ao longo de toda a vida.

As trocas intersubjetivas envolvem um tipo especial de prazer. Estados de intersubjetividade a dois são buscados pelas crianças pequenas, por si mesmos, pela mera compreensão e pelo mero compartilhamento. Estamos diante de padrões intrinsecamente motivados. Novamente, essa motivação social elementar nos acompanha por toda a vida. Modelos cognitivistas e individualistas tendem a negligenciar essa interface entre a mente humana individual e seu habitat sócio-cultural (Rommetveit, 1998).

O foco no ajustamento intersubjetivo emocionalmente regulado contrasta com focos estritamente cognitivos. Consideramos apropriada a posição de Trevarthen (1998), que recentemente retomou a questão destacando a intersubjetividade emocional como precedente e inseparável da intersubjetividade intelectual.

Embora não use o termo "intersubjetividade", Tomasello (2003) indica a capacidade de assumir a perspectiva mental do outro como uma característica básica selecionada no processo da evolução humana, entendida como a chave sócio-cognitiva da cultura. Esse traço garante a participação do indivíduo na coletividade, o que ele ilustra mencionando a afirmação de Newton: "A criança vê tão longe porque está de pé sobre os ombros de um gigante". Prosseguindo no argumento, considera que crianças autistas não seriam capazes de tirar vantagem da sabedoria coletiva por não possuírem as habilidades sócio-cognitivas necessárias, por motivos biológicos. Por sua vez, crianças hipoteticamente criadas em isolamento, se sobrevivessem, também não poderiam usufruir dessa sabedoria.

Seja com foco na emoção, seja com foco na cognição, ao acompanhar o bebê em crescimento, descobrimos que os novos marcos típicos do desenvolvimento da criança também estão associados a questões intersubjetivas, peculiarmente humanas. Embora compartilhemos com os primatas, animais 
sociais por excelência, compreensões complexas de relações sociais, temos como característica distintiva uma forma típica de compreensão do outro. Somos capazes de nos colocar no lugar do outro e de assumir a perspectiva mental do outro de um modo muito particular. Por exemplo, somos capazes de um pequeno gesto que falta aos demais primatas e que à primeira vista pode parecer muito singelo, e nem significar muita coisa. Eles não apontam objetos, nem os exibem, nem os oferecem ativamente. Esses gestos protodeclarativos traem uma de nossas características mais fundamentais, que é a de compartilhadores de atenção. Temos uma motivação intrínseca para o compartilhamento de atenção, cuja ausência também é um diagnóstico para o autismo, assim como a relativa ausência de brincadeiras de faz-de-conta, características relacionadas à dificuldade em assumir a perspectiva mental do outro (Tomasello, 2003).

Sinais típicos de desenvolvimento de uma "teoria da mente" do outro na criança aparecem aos nove meses, com o apontar objeto protodeclarativo. Apontar e alcançar objetos, acompanhar o olhar do outro e usar a expressão emocional do outro para guiar o próprio comportamento (revisão em Adamson, 1996) são comportamentos que envolvem capacidade de atenção conjunta, ou seja, coordenação da atenção de duas ou mais pessoas em torno de um foco de interesse. A criança que acompanha o olhar de um adulto está compartilhando com ele o foco de atenção. A criança que aponta para algo está favorecendo o compartilhar de sua atenção com um adulto. Isso fornece uma janela para a mente do outro e, subseqüientemente, possibilita o ajustamento à posição do outro (Baron-Cohen, 1995). É esse novo tipo de encontro com o outro que constitui a "revolução dos nove meses" (Tomasello, 2003), quando, construída pela história interacional desde o nascimento, emerge uma maneira qualitativamente nova da criança entender seu mundo e, em especial, seu mundo social.

Entre outros primatas, a comunicação parece sempre voltada a produzir um determinado resultado no outro, como abrir uma porta, dar um brinquedo, além de pedir comida, os chamados gestos protoimperativos (Gómez, 1989), estando ausentes padrões sem intenção aparente de ação, os gestos protodeclarativos que são apresentados por bebês.

Os estudos comparativos de intersubjetividade ajudam na compreensão das origens do traço e das especificidades dessa característica no ser humano. O estudo de casos em que alguns aspectos da intersubjetividade estão 
prejudicados, como ocorre nas síndromes de desenvolvimento global ou autísticas, adicionam elementos para a formulação de questões e para o entendimento do fenômeno.

A imitação também está comprometida em crianças autistas. Revisão de estudos feita por Rogers e Pennington (1991) mostrou dificuldades na imitação de movimentos do corpo e da manipulação de objetos, na expressão de afetos e na imitação simbólica. Esses autores consideraram a imitação como fundamental para o desenvolvimento normal da teoria da mente. A partilha de emoções e a teoria da mente são deficientes no autismo. Tais capacidades estariam envolvidas na formação e na coordenação da representação social do outro e de si mesmo em níveis de crescente complexidade. Porém, os resultados não são simples: algumas vezes os déficits não são encontrados, em outras, restringem-se às imitações simbólicas. Whiten e Brown (1998) encontraram em crianças autistas deficiências na imitação espontânea, na imitação adiada e na imitação estimulada, bem como dificuldades nos testes de reversão ou simbólicos. Os resultados sugerem falta da motivação ou da atenção que levam os sujeitos normais à imitação espontânea. A intervenção sugerida é estimular o engajamento intersubjetivo. É interessante notar que, no caso da síndrome de Asperger, que faz parte dos quadros de autismo, as pessoas apresentam, às vezes, capacidades acima do normal com a física cotidiana; interessam-se por objetos e por luzes. Por outro lado, no caso da síndrome de Williams, que pertence a outro espectro, a cognição espacial e a memória estão prejudicadas, enquanto a linguagem e a teoria da mente se apresentam normais. É evidente que a compreensão dessas síndromes requer cuidados e reúne um conjunto complexo de informações e de possibilidades. Esse raciocínio elucida a existência de domínios relativamente independentes e ajuda na compreensão da capacidade de encontro com o outro nos vários aspectos do desenvolvimento. Crianças com síndrome de Asperger são boas sistematizadoras, como é revelado pelo seu desempenho na física cotidiana, mas são más empatizadoras. Têm muita dificuldade em passar por testes de teoria da mente, mas se saem bem nos testes que envolvem compreensões espaciais. Leituras de histórias que envolvem empatia ativam determinadas áreas cerebrais enquanto histórias de objetos ativam outras áreas, nas crianças de um modo geral; nas crianças autistas, as áreas correspondentes da empatia não são ativadas (revisão em Ridley, 2003). 
Vera Silvia Raad Bussab, Maria Isabel Pedrosa e Ana Maria Almeida Carvalho

\section{Empatia}

Comportamentos de cuidado, de conforto, de defesa, por exemplo, observados em situação de interação criança-criança, evidenciam um processo psicológico que tem sido chamado na literatura de "empatia". O surgimento destes comportamentos numa idade muito precoce, já no primeiro ano de vida, instiga uma reflexão sobre a sua natureza e sua função e sobre os mecanismos que os constituem. (Pedrosa, 1996, p. 50)

O que é empatia? A teorização psicológica clássica deu pouco espaço à pesquisa sobre esse fenômeno nos primeiros anos de vida, possivelmente devido à força da suposição teórica prevalente de que crianças pequenas não seriam capazes, cognitivamente, de responder a emoções de outros. Essa suposição respalda-se, por exemplo, em Piaget $(1956,1977)$ e em Piaget e Inhelder (1980), que caracterizaram a criança no estágio inicial de seu desenvolvimento como cognitivamente egocêntrica, incapaz de se colocar no ponto de vista do outro e, conseqüentemente, incapaz de coordenar pontos de vista distintos; esse egocentrismo seria superado por um processo de decentração do eu, evidenciado em torno dos sete anos.

A empatia é geralmente concebida como um fenômeno que propicia ao sujeito "colocar-se no lugar do outro" ou "sentir o que o outro sente, na perspectiva do outro" ou, então, é apresentada como "uma resposta de uma pessoa ao estado afetivo de outra" (cf., por exemplo, Bastos \& Carvalho, 1992, p. 114). A empatia não é um comportamento observável 'per se', e sim um estado inferido a partir de evidências indiretas, tais como a orientação de um comportamento para um objetivo, suas consequiências, a consistência de certas relações estabelecidas em um certo intervalo de tempo e a natureza das reações dos parceiros ao comportamento do outro (Pedrosa, 1996).

É quando se desloca o foco do aspecto cognitivo para o aspecto afetivo-emocional que o fenômeno da empatia passa a fazer sentido e tornar-se reconhecível na criança pequena. Plutchik (1990) supõe que as emoções são mecanismos comunicativos que todos os organismos usam no esforço de sobrevivência; a empatia seria, segundo ele, "um tipo de processo de indução pelo qual emoções, positivas e negativas, são compartilhadas e através do qual aumenta a chance de ocorrerem comportamentos similares nos participantes. Assim dois indivíduos podem compartilhar sentimentos de medo, de afeição ou 
de hostilidade" (p. 43). Pode-se conceber a empatia como um componente de sinalização ou comunicação afetiva, acionado por uma diversidade de displays observados em várias espécies animais. "A essência da resposta empática é a comunicação de um estado emocional de um organismo para o outro" (p. 40).

Animais de várias espécies, assim como seres humanos, exibem muitos tipos de displays relacionados a tipos específicos de interações. Para Plutchik (1990), displays são comportamentos conspícuos (sinais amplificados, especialmente nítidos), relacionados a eventos emocionais importantes: congratulação, cortejamento, dominância/submissão, alarme, desafio, desconforto etc., tendo em comum a alta probabilidade de induzir sentimentos similares e comportamentos nos indivíduos que expressam e percebem o display.

Nadel e Fontaine (1989) referem-se a um sistema de trocas sociais anteriores à linguagem verbal, que denominam sistema emocional, e que seria seguido pelo sistema imitativo e posteriormente pelo sistema cooperativo. Esses sistemas seriam transitórios e teriam papel funcional em cada nível de adaptação em que a criança se encontra.

É possível supor que a criança, antes de revelar comportamentos empáticos, tenha necessariamente sentido as mesmas disposições e experiências subjetivas para reconhecer seus indícios no outro e, desse modo, poder sintonizar com ele, revivendo suas próprias impressões. Wallon (1934/1971b) considera essa possibilidade pouco provável, posto que o fenômeno, que ele chamou de simpatia, já pode ser observado entre um e dois anos de idade, período em que as experiências da criança ainda não seriam muito diversificadas.

O episódio descrito no início deste texto serve de mote para essa reflexão. Como se pode explicar aquela sequiência de comportamentos em crianças tão pequenas? O que significa para Lucas a expressão de desconforto de Mário? Lucas reagiu com surpresa? Aconteceu um fenômeno de projeção, ou de auto-referência? E o que significa para Mário o gesto de tocar, mesmo desajeitado, de Lucas? Ele se sentiu confortado, surpreendido ou simplesmente manipulado, como se fosse um objeto de curiosidade?

Para Wallon (1934/1971a; 1942/1979), o que assegura os primórdios das relações sociais entre os indivíduos é o caráter contagioso das manifestações afetivas, cuja função parece ser a de exercer uma ação sobre o outro, 
de provocar harmonia de reação e de impulso, ou comportamentos análogos. A mímica, o modo de expressão da pessoa, é considerada "a função postural apropriada às necessidades das relações afetivas entre indivíduos" (Wallon, 1934/1971a, p. 228). É por meio da mímica que a criança ajusta as suas disposições às dos seus parceiros, reconhecendo a si nos outros e aos outros em si própria (Pedrosa, 1996).

Wallon (1934/1971b) distingue a simpatia do mimetismo afetivo, do qual ela procede, e do altruísmo que é, em parte, constituído a partir dela. No mimetismo afetivo, a criança se confunde com o outro; é o caso, por exemplo, de uma criança que chora quando outra começa a chorar. Aos poucos, as reações mímicas e a aprendizagem do meio circundante a conduzem a uma espécie de desdobramento em que há indícios de que está havendo um sentimento de uma certa diferença entre ela e o outro: é como se as emoções sentidas não se justificassem por ela própria. Delineia-se a simpatia (pathos - sentir ou sofrer; sim - com), estado caracterizado por esse desdobramento, onde a criança tenta distribuir fora de si aquilo que lhe parece estranho. As repetições de ações, os comportamentos de perseguir e ser perseguido, de dar e tomar, de esconder e de procurar são exemplos do que parece ser um jogo de experimentação, em que a criança tenta descobrir os aspectos opostos ou complementares e, dessa maneira, experienciar as emoções correspondentes de um e de outro lado. Esse jogo de alternância em que a criança aprende a dissociar-se, a separar as situações que lhe tocam, que lhe dizem respeito, mas que não são exatamente suas, e sim do outro, propicia, parcialmente, o aparecimento do altruísmo (Pedrosa, 1996).

Nessa perspectiva, o altruísmo aparece como um traço próprio da sociabilidade humana (mas não apenas dela - a pesquisa comparativa oferece inúmeros exemplos, cf. Alcock, 2001; Trivers, 1971) e não como uma conquista culturalmente arbitrária e imposta de fora para dentro.

Da mesma forma que na revisão acima sobre intersubjetividade, destacam-se aqui as diferenças de ênfase, de um lado em aspectos cognitivos, de outro em aspectos afetivo-emocionais, mediados pelas sensações, percepções e expressões corporais, e anteriores à linguagem verbal.

Como articular as literaturas sobre intersubjetividade e sobre empatia? Em primeiro lugar, pensamos que, a partir do momento em que as dimensões afetivo-emocionais assumem o papel de figura, há uma convergência dessas 
literaturas rumo a uma concepção de bebê que articula biologia e cultura, preparação biológica e experiência, em um mesmo complexo adaptativo: como vimos no primeiro item deste texto, o de um ser cuja agenda consiste prioritariamente no encontro com o outro, e que nasce equipado para esse encontro. Intersubjetividade e capacidade de empatia são parte desse equipamento, que se concretizará funcionalmente através de encontros com o outro.

Por outro lado, a literatura sobre empatia parece se concentrar em um universo mais delimitado de fenômenos: a ajuda, o consolo, a solidariedade e outros que, em literaturas de outras origens, são chamados "comportamentos pró-sociais"6. O conceito de intersubjetividade, por sua vez, refere-se a um fenômeno mais geral, subjacente a toda interação e comunicação humanas. Nesse sentido, pode-se pensar a empatia como uma de suas manifestações, e a intersubjetividade como aquilo que a possibilita.

Revendo nosso episódio à luz das considerações feitas nos dois últimos itens, as ações de Lucas e a reação de Mário parecem tornar-se mais compreensíveis do ponto de vista motivacional e perceptual. Alguns elos, no entanto, ficam em aberto; entre eles, de certa forma, as próprias ações: o gesto de consolo de Lucas, a sequiência de brincadeira que se configura posteriormente. Seguindo as pistas indicadas nos dois últimos itens, e particularmente as de Wallon e de Nadel e Baudonnière, apontadas acima, a literatura sobre imitação parece ser um caminho possível nessa direção.

\section{Imitação}

Já revimos, em item anterior, a evidência inquestionável, e até emocionante, de ocorrência de imitação desde as primeiras horas de vida. Ao longo dos três primeiros anos, a imitação se diferencia em várias modalidades e constitui um dos mecanismos fundamentais de comunicação, tanto na interação adulto-criança como na interação criança-criança (cf., por exemplo, Nadel

6 Embora essa expressão já esteja consagrada e seja facilmente compartilhável, preferimos evitar seu uso, pela implicação valorativa de oposição a comportamento "antisocial” (agressão, conflito etc). Em nossa perspectiva, essa oposição não faz sentido: qualquer evento interativo é social, e tem funções adaptativas - ainda que sempre bem ajustadas do ponto de vista individual - de regulação social (Carvalho, 1992; Carvalho, Império-Hamburger \& Pedrosa, 1998). 
\& Baudonnière, 1981). Curiosamente, a imitação foi abandonada pelos pesquisadores durante um período significativo em meados do século XX, descartada como um processo pouco relevante do ponto de vista do desenvolvimento cognitivo, foco da pesquisa nesse período. É a partir dos anos 70 que esse conceito volta com força à teorização psicológica, especialmente em relação ao desenvolvimento nos primeiros anos de vida. Em decorrência disso, já se acumulou uma literatura extensa a respeito desse fenômeno e de seu papel no desenvolvimento.

Diversas funções têm sido atribuídas à imitação neonatal. Para Papousek e Papousek (1984), a igualação expressiva por parte do adulto, ou seja, a imitação da criança pelo adulto, já exaustivamente documentada, funciona como um espelho e um eco biológicos, que permite o desenvolvimento da auto-consciência e da intencionalidade na criança, apontando para as relações entre o desenvolvimento cognitivo e as trocas sociais cotidianas da criança pequena. Parece ser de aceitação geral a idéia de que a imitação serve para facilitar a aquisição de novos comportamentos, que é considerada uma das funções primárias da imitação na infância, de um modo geral. Evidências podem ser arroladas. Embora as igualações iniciais dos bebês pareçam envolver padrões que já existem em seus repertórios, os limites entre o que é ou não criativo podem não ser tão simples. Além disso, tem ficado claro que também ocorrem imitações de padrões inusitados. Bebês de seis semanas conseguem modificar um de seus comportamentos naturais, protrusão de língua, movendo-a com empenho de um lado para o outro da boca, de modo semelhante ao exibido por um adulto (Meltzoff \& Moore, 1994).

A importância do próprio compartilhamento para o desenvolvimento da linguagem tem sido reconhecida na maioria das teorias vigentes (por exemplo, Karmiloff-Smith, 1995; Tomasello, 2003), para as quais a aquisição de símbolos lingüísticos intersubjetivamente compreendidos exige a participação em cenas de atenção conjunta que estabelecem bases sócio-cognitivas essenciais. Requer, ainda, o entendimento das intenções comunicativas, nas quais alguém quer que ela preste atenção em algo na cena.

A função da sincronia interacional, que a nosso ver está ligada ao fenômeno da igualação, foi relacionada à aculturação e à aquisição da linguagem (Condon \& Sander, 1974): via sincronização, ocorre um acesso privilegiado, 
através do qual a linguagem é dançada e refletida numa organização neural, antes mesmo de ser completamente compreendida ou produzida.

Têm sido também aventadas algumas outras funções da imitação neonatal, ajustadas a essa fase do desenvolvimento inicial e não necessariamente ligadas à aquisição de habilidades específicas para o futuro. Jacobson (1979) sugeriu facilitação da amamentação. A função de comunicação pré-lingüística e de promoção da interação mãe-bebê, nessa fase especial do desenvolvimento, foi apontada por Bjorklund (1987), entre outros, o que foi corroborado pela descoberta de correlação entre o grau de imitação neonatal e a qualidade da interação mãe-bebê três meses mais tarde; a função de imitação como um meio preponderante de comunicação foi apontada por Nadel e Baudonnière (1981) na interação criança-criança no terceiro ano de vida.

Uma descoberta adicional acrescentou outros entendimentos para o papel da imitação precoce. Ao reencontrar um parceiro de interação, bebês de seis semanas são capazes de reproduzir a expressão apresentada na véspera pelo parceiro em questão. Desse modo, a imitação envolve mais do que percepção e coordenação sensório-motora intermodal: liga-se também à memória e ao reconhecimento individual. $\mathrm{O}$ bebê de seis semanas gera ações, com base na memória, 24 horas depois, ilustrando uma forma primitiva de memória não-verbal. Para Meltzoff e Moore (1994), crianças pequenas fazem o que os pais fazem e não o que os pais dizem. Os autores interpretaram essa reapresentação de igualação prévia como um teste usado pela criança para saber quem é o parceiro. Para eles, a imitação existe para entender pessoas, assim como a manipulação física - sacudir, pegar, mexer, jogar - existe para o entendimento de objetos. Seria um modo primitivo de compreensão e de comunicação. Poderíamos supor ainda que esse seria um modo de retomar a construção de uma relação individualizada, do tipo "sei quem você é e lembro do que fizemos juntos".

Carvalho e Pedrosa (no prelo) apresentam uma revisão a respeito de imitação a partir de três vertentes da literatura, que aqui tocamos apenas de passagem: autores interacionistas clássicos, como Wallon e Piaget; a literatura recente sobre imitação em primatas; e a teorização sobre o papel da imitação no desenvolvimento de ações coordenadas na interação criança-criança (Eckerman, Davis, \& Didow, 1989; Eckerman \& Didow, 1996; Eckerman \& 
Peterman, 2001). As autoras sugerem que os atos imitativos podem ser compreendidos como uma proto-linguagem em dois sentidos diferentes mas compatíveis: como recursos comunicativos que emergem antes da linguagem verbal e/ou como precursores ou requisitos do processo de desenvolvimento que conduz à representação e à linguagem. É principalmente no primeiro desses sentidos que parece possível explorar um pouco mais o episódio descrito.

A sequiência lúdica desenvolvida entre Mário e Lucas ao pé do berço, na segunda parte do episódio, apresenta os componentes motivacionais e cognitivos da chamada "imitação verdadeira", mediada por atenção conjunta a aspectos selecionados do ambiente e envolvendo a reprodução de ações em termos de morfologia e orientação. Essa imitação "de meios" (e não apenas de "fins") é considerada por alguns autores como uma modalidade caracteristicamente humana do imitar, e um requisito ou possibilitador da aquisição da linguagem (Tomasello, 1988; Tomasello, Kruger, \& Ratner, 1993). Ao mesmo tempo, sua função imediata é claramente de comunicação e construção de compartilhamento. O compartilhamento, como apontam Carvalho e Rubiano (2004), é simultaneamente criador e criatura, ou instrumento e produto, de vínculos interpessoais, que permitem a persistência do que é compartilhado e seu desdobramento em novas coisas compartilhadas. Vínculo, como indicado acima, implica uma individualização do outro - sei quem você é e o que fizemos juntos - como sugere Lucas ao acompanhar Mário com o olhar quando ele se afasta no final da seqüência.

E quanto ao gesto de "afago" de Lucas? Evidentemente não se pode descartar a possibilidade de que tenha sido um gesto apenas casualmente semelhante ao gesto adulto. Mas é provocante imaginar que, tal como o bebê de seis semanas que reproduz uma expressão presenciada na véspera, Lucas, aos nove meses, tenha memórias de gestos de conforto experienciados que reproduz, não apenas com seu corpo, mas de maneira adequadamente orientada para o corpo do outro.

\section{Lucas, Mário, e o que eles nos ensinam}

Não é fácil produzir demonstrações decisivas sobre as funções imediatas ou de longo prazo dos padrões de comportamento. Tampouco se deve 
esperar por relações causais lineares simples entre determinadas experiências e certas características do desenvolvimento subseqüente. Os efeitos podem ser indiretos, sutis, cumulativos, múltiplos, envolvendo emoções e afetos e ainda sujeitos a retroalimentação complexa. Importa notar que essas hipóteses funcionais inspiram pesquisas, produzem explicações alternativas, desafiam concepções indevidamente cristalizadas de desenvolvimento e convidam para uma visão integrada de aspectos emocionais e cognitivos. Parece que estamos diante de processos que ainda não entendemos plenamente. É tentadora, por exemplo, a suposição de Stern (1985) de que a imitação de estados emocionais dos outros por meio de uma "sintonização afetiva" pode refletir um profundo processo de identificação.

Merecem um destaque especial, nessa discussão, a inseparabilidade entre aspectos emocionais e cognitivos da intersubjetividade, a motivação intrínseca para o compartilhamento, a presença muito precoce, ainda que rudimentar, de uma intersubjetividade, e as transformações ontogenéticas que permitem o desenvolvimento de uma teoria da mente, bem como a questão da imersão cultural via compartilhamento.

Vivemos um momento especial para a compreensão das características humanas básicas, graças à conjunção de esforços de muitas áreas de pesquisa. Não deixa de ser interessante que estejamos identificando, num dos processos mais fundamentalmente relacionados à nossa natureza biologicamente social, uma composição de fenômenos que envolvem ao mesmo tempo cognição, afeto e emoção, ligados a vínculo e compartilhamento e ao encontro com o outro.

Bussab, V. S. R., Pedrosa, M. I., \& Carvalho, A. M. A. (2007). Encounters: Empathy and intersubjectivity in the first year of life. Psicologia USP, 18(2), 99-132.

\begin{abstract}
The observation of a caretaking episode among two children aged 9 and 18 months has launched a reflection on the ontogeny of empathy. In this paper, this episode is described and some theoretical questions it evoked are raised, regarding conceptions about children and development, ontogeny of communication and cultural life. Subsequently, the literature on socio-affective and cognitive development
\end{abstract}


Vera Silvia Raad Bussab, Maria Isabel Pedrosa e Ana Maria Almeida Carvalho

in the first year of life is reviewed from the psychoethological and socioconstructivist perspectives, placing some emphasis on Henri Wallon's contribution. Three concepts are highlighted: intersubjectivity, empathy and imitation. This literature depicts the human neonate as an organism which is biologically organized for socio-cultural life since birth, or even from the moment of conception, through its pre-adaptedness for encounters with other human beings and for social exchanges, which are constitutive conditions of individual development.

Index terms: Empathy. Intersubjectivity. Imitation. Infants. Human development.

Bussab, V. S. R., Pedrosa, M. I., \& Carvalho, A. M. A. (2007). Rencontre avec l'autre: empathie et intersubjectivité pendant la première année de vie. Psicologia USP, 18(2), 99-132.

Résumé: L'observation d'un épisode de soin entre deux enfants de moins de dix-huit mois est à l'origine d'une réflexion sur l'ontogenèse de l'empathie. L'épisode est décrit et, à la suite, on pose des questions théoriques relatives à certaines conceptions sur l'enfant et son processus de développement, ainsi que sur l'ontogenèse de la communication et de la vie culturelle. Sous cet angle, on propose une revue de la littérature consacrée au développement socio-affectif et cognitif au cours de la première année de vie, à travers une perspective psycho-éthologique et socio-constructiviste, en soulignant la contribution d'Henri Wallon, en particulier trois concepts: l'intersubjectivité, l'empathie et l'imitation. Cette littérature dépeint le nouveau-né humain comme un être biologiquement organisé pour la vie socio-culturelle, dans laquelle il est plongé depuis sa naissance - ou même depuis la conception - grâce à sa pré-organisation pour la rencontre avec l'autre et pour les échanges sociaux, conditions constitutives de son développement individuel.

Mots-clés: Empathie. Intersubjectivité. Imitation. Bébé. Développement humain. 
Encontros com o Outro: Empatia e Intersubjetividade no Primeiro Ano de Vida

\section{Referências}

Adamson, L. B. (1996). Communication development during infancy. Boulder, NV: Westview.

Ades, C. (1998). A mirror for the self. Ciência e Cultura, 50, 123-128.

Alcock, J. (2001). Animal behavior - an evolutionary approach. Sunderland, MA: Sinauer.

Baron-Cohen, S. (1995). Mindblindness: An essay on autism and theory of mind. Cambridge, MA: MIT Press.

Bastos, M.F., \& Carvalho,A.M.(1992, outubro). Empatia entre crianças. Trabalho apresentado no Simpósio "Comportamento pró-social: questões filogenéticas e ontogenéticas" da XXI Reunião Anual de Psicologia da SBP (pp. 114-116). Ribeirão Preto, SP.

Bergamasco, N. H. P. (1997). Expressão facial como acesso à consciência do recém-nascido. Psicologia USP, 8(2), 275-286.

Bjorklund, D. F. (1987). A note on neonatal imitation. Developmental Review, 7, 86-92.

Bowlby, J. (1969/1984). Apego e perda. Vol. 1: Apego. São Paulo: Martins Fontes.

Bråten, S. (1998). Infant learning by altercentric participation: The reverse of egocentric observation in autism. In S. Bråten (Ed.), Intersubjective communication and emotion in early ontogeny (pp. 105-124). Cambridge: Cambridge University Press.

Bussab, V. S. R (2003). Afetividade e interação social em crianças: abordagem psicoetológica. Tese de Livre Docência, Instituto de Psicologia, Universidade de São Paulo, São Paulo.

Camaioni, L. (1980). L’interazione tra bambini. Roma: Armando Armando.

Carvalho, A. M. A. (1988). Algumas reflexões sobre o uso da categoria "interação social”. In Anais da XVIII Reunião Anual de Psicologia (pp. 511-515). Ribeirão Preto, SP.

Carvalho, A. M. A. (1988, outubro). Etologia das relações mãe-criança no ser humano. In Anais do VI Encontro Anual de Etologia (pp. 39-45). Florianópolis, SC.

Carvalho, A. M. A. (1989). Brincar juntos: natureza e função da interação entre crianças. In C. Ades (Org.), Etologia - de animais e de homens (pp. 199-210). São Paulo: Edusp.

Carvalho, A. M. A. (1992). Comportamento pró-social: questões conceituais. Trabalho apresentado no Simpósio "Comportamento pró-social: questões filogenéticas e ontogenéticas” da XXI Reunião Anual de Psicologia da SBP (pp. 112-114). Ribeirão Preto, SP.

Carvalho, A. M. A., \& Beraldo, K. E. A. (1989). Interação criança-criança: ressurgimento de uma área de pesquisa e suas perspectivas. Cadernos de Pesquisa (FCC), 71, 55-61. 
Vera Silvia Raad Bussab, Maria Isabel Pedrosa e Ana Maria Almeida Carvalho

Carvalho, A. M. A., Império-Hamburger, A., \& Pedrosa, M. I. (1998). Interaction, regulation and correlation in the context of human development: Conceptual discussion and empirical examples. In M. Lyra \& J. Valsiner (Eds.), Child development within culturally structured environments. Vol. 4: Construction of psychological processes in interpersonal communication (pp. 155-180). Stamford, CT: Ablex.

Carvalho, A. M. A., Magalhães, C. M. C., Pontes, F. A. R., \& Bichara, I. (Orgs.). (2003). Brincadeira e cultura: viajando pelo Brasil que brinca. São Paulo: Casa do Psicólogo.

Carvalho, A. M., \& Pedrosa, M. I. (1993, Jully 19-23). Comforting behaviour in young children: Implications for the ontogeny of empathy. In Twelfth Biennial Meetings of ISSBD (p. 38). Recife.

Carvalho, A. M. A., \& Pedrosa, M. I. (no prelo). Precursores filogenéticos e ontogenéticos da linguagem: reflexões preliminares. Revista do CFH da UFSC.

Carvalho, A. M. A., \& Rubiano, M. R. B. (2004). Vínculo e compartilhamento na brincadeira de crianças. In M. C. Rossetti-Ferreira, K. Amorim, A. P. Silva e A. M. A. Carvalho (Orgs.), Rede de significações e o estudo do desenvolvimento humano (pp. 171-187). Porto Alegre: Artes Médicas.

Condon, W. S., \& Sander, L. W. (1974). Synchrony demonstrated between movements of the neonate and adult speech. Child Development, 54, 456-462.

Csillag, S. (1997). Os três primeiros dias de vida - uma observação dos estados comportamentais do bebê recém-nascido. Tese de Doutorado, Instituto de Psicologia, Universidade de São Paulo, São Paulo.

Darwin, C. (1872/1995). The expression of emotions in man and animals. New York: Philosophical Library.

Dunn, J. (1988). The beginnings of social understanding. Oxford, UK: Basil Blackwell.

Durnham, P. J., Durnham, F., Hurshman, A., \& Alexander, T. (1989). Social contingencies effects of subsequent perceptual-cognitive tasks in young infants. Child Development, 60, 1486-1496.

Eckerman, C. O., Davis, C. C., \& Didow, S. M. (1989). Toddlers' emerging ways of achieving social coordinations with a peer. Child Development, 60, 440-453

Eckerman, C. O., \& Didow, S. M. (1996). Nonverbal imitation and toddlers' mastery of verbal means of achieving coordinated action. Developmental Psychology, 32(1), 141-152.

Eckerman, C., Oehler, J. M., Medvin, M. B., \& Hannan, T. E. (1994). Premature newborns as social partners before term age. Infant Behavior and Development, 17, 55-70.

Eckerman, C. O., \& Peterman, K. (2001). Peers and infant social/communicative development. In G. Bremner \& A. Fogel (Eds.), Blackwell handbook of infant development. Oxford, UK: Blackwell. 
Encontros com o Outro: Empatia e Intersubjetividade no Primeiro Ano de Vida

Eibl-Eibesfeldt, I. (1989). Human ethology. New York: Aldine de Gruyter.

Fantz, R. L. (1963). Pattern vision in newborn infants. Science, 140, 296-297.

Field, T. M., Cohen, D., Garcia, R., \& Greenberg, R. (1984). Mother strange discrimination by newborn. Infant Behavior and Development, 7, 19-25.

Field, T., Guy, L., \& Umbei, V. (1985). Infant's responses to mother imitative behavior. Infant Mental Health Journal, 6(1), 40-44.

Field, T. M., Woodson, R., Greenberg, R., \& Cohen, D. (1982). Discrimination and imitation of facial expressions by neonates. Science, 218, 179-181.

Gómez, J. C. (1989). La comunicación y la manipulación de objetos en crías de gorila. Estudios de Psicología, 38, 111-128.

Goodman, N. (1978). Ways of worldmaking. Hassocks: Harvester Press.

Hoffman, M. L. (1981). Is altruism part of human nature? Journal of Personality and Social Psychology, 40, 121-137.

Jacobson, S. W. (1979). Matching behavior in the young infant. Child Development, 50, 425-430.

Karmiloff-Smith, A. (1995). Beyond modularity - a developmental perspective on Cognitive Science. Cambridge, MA: MIT Press.

Klaus, M. H., \& Kennell, J. H. (1992). Pais/bebê: a formação do apego. Porto Alegre: Artes Médicas.

Kugiumutzakis, G. (1998). Neonatal imitation in the intersubjective companion space. In S. Bråten (Org.), Intersubjective communication and emotion in early ontogeny (pp. 6388). Cambridge: Cambridge University Press.

Lordelo, E. R., \& Carvalho, A. M. A. (1989). Comportamento de cuidado entre crianças: uma revisão. Psicologia: Teoria e Pesquisa, 5(1), 1-19.

Lyra, M. C. D. P., \& Souza, M. (2003). Dynamics of dialogue and emergence of self in early communication. In I. E. Josephs \& J. Valsiner (Eds.), Dialogicality in development. Vol. 5: Child development in culturally structured environments (pp. 51-68). Stamford, CT: Greenwood.

MacFarlane, J. (1975). Olfaction in the development of social preferennces in the human neonate. In M. Hofer (Ed.), Parent-Infant Interaction. Amsterdam: Elsevier.

Meltzoff, A. N., \& Moore, M. K. (1977). Imitation of facil and manual gestures by human neonates. Science, 198, 75-78.

Meltzoff, A. N., \& Moore, M. K. (1983). Newborn infants imitate adult facial gestures. Child Development, 54, 702-709. 
Vera Silvia Raad Bussab, Maria Isabel Pedrosa e Ana Maria Almeida Carvalho

Meltzoff, A. N., \& Moore, M. K. (1994). Imitation, memory, and the representation of persons. Infant Behavior and Development, 17, 83-99.

Meltzoff, A. N., \& Moore, M. K. (1998). Object representation, identity, and the paradox of early permanence. Infant Behavior and Development, 21, 200-236.

Mizukami, K., Kobayashi, N., Ishii, T., \& Iwata, H. (1990). First selective attachment begins in early infancy. A study using telethermography. Infant Behavior and Development, 14(3), 231-257.

Murray, L. (1980). The sensitivities and expressive capacities of young infants in communication with their mothers. Tese de Doutorado, University of Edinburgh.

Murray, L. (1998). Contributions of experimental and clinical perturbations of motherinfant communication to the understanding of infant intersubjectivity. In S. Bråten (Ed.), Intersubjective communication and emotion in early ontogeny (pp. 127-143). Cambridge: Cambridge University Press.

Murray, L., \& Andrews, L. (2000). The social baby. Richmond, UK: CP Publishing.

Murray, L., \& Trevarthen, C. (1985). Emotional regulation of interactions between twomonth-olds and their mothers. In T. M. Field \& N. A. Fox (Eds.), Social perception in infants (pp. 177-197). Norwood, NJ: Ablex.

Nadel, J., \& Baudonière, P. M. (1981). Imitação, modo preponderante de intercâmbio entre pares durante o terceiro ano de vida. Cadernos de Pesquisa, 39, 26-31.

Nadel, J., \& Fontaine, A. (1989). Communicating by imitation: A developmental and comparative approach to transitory social competence. In B. H. Schneider et al. (Eds.), Social competence in developmental perspective (pp. 131-144). New York: Kluwer Academic.

Oliva, A. D. (2001). Papel do input e da intersubjetividade na aquisição de linguagem: proposta de um modelo explicativo. Teses de Doutorado, Instituto de Psicologia da Universidade de São Paulo, São Paulo.

Otta, E. (1994). O sorriso e seus significados. Petrópolis, RJ: Vozes.

Papousek, M., \& Papousek, H. (1984). Learning and cognition in the every day life of human infants. Advances in the Study of Behavior, 14, 127-159.

Pedrosa, M. I. (1996). A emergência de significados entre crianças nos anos iniciais de vida. In M. I. Pedrosa (Org.), Coletâneas da ANPEPP. Investigação da criança em interação social (Vol. 1(4), pp. 49-67). Recife: Ed. Universitária da UFPE.

Piaget, J. (1956). Os fatores sociais do desenvolvimento intelectual. In Psicologia da inteligência (Cap. 6, pp. 201-213). Rio de Janeiro: Fundo de Cultura.

Piaget, J. (1977). O julgamento moral na criança. São Paulo: Mestre Jou. 
Encontros com o Outro: Empatia e Intersubjetividade no Primeiro Ano de Vida

Piaget, J., \& Inhelder, B. (1980). A psicologia da criança (6a ed.). São Paulo: Difel.

Plutchik, R. (1990). Evolutionary bases of empathy. In N. Eisenberg \& J. Strayer (Eds.), Empathy and its development. New York: Cambridge University Press.

Ribas, A. F. P., \& Seidl de Moura, M. L. (1998). Interações precoces mãe-bebê: a gênese de zonas de construção. Cadernos de Psicologia, 9, 59-75.

Ridley, M. (2003). Nature via nurture. New York.: Harper Collins.

Rogers, S. J., \& Pennington, B. F. (1991). A theoretical approach to the deficits in infantil autism. Development and Psychopathology, 3, 137-162.

Rommetveit, R. (1998). Intersubjective attunement and linguistically mediated meaning in discourse. In S. Bråten (Ed.), Intersubjective communication and emotion in early ontogeny (pp. 372-382). Cambridge: Cambridge University Press.

Santana, P. H., Otta, E., \& Bastos, M. F. (1993). Um estudo naturalístico de comportamentos empáticos em pré-escolares. Psicologia: Teoria e Pesquisa, 9(3), 575-586.

Schaal, B., Montagner, H., Hertling, E., Bolsoni, D., Moyse, A., \& Quichon, A. (1980). Les stimulations olfatives dans les relations entre lénfant et la mere. Reprodution, Nutrition et Development, 20, 843-858.

Seidl de Moura, M. L. (1999). Interações iniciais e seu papel no desenvolvimento: uma contribuição ao estudo da gênese da atividade mediada. Tese de professor titular em desenvolvimento cognitivo. Universidade do Estado de Rio de Janeiro, Rio de Janeiro.

Seidl de Moura, M. L., \& Ribas, A. F. P. (2000). Desenvolvimento e contexto sócio-cultural: a gênese da atividade mediada nas interações mãe- bebê. Psicologia: Reflexão e Crítica, $13(2), 245-256$.

Stern, D. N. (1985). The interpersonal world of the infant. New York: Basic Books.

Tomasello, M. (1988). The role of joint attention in early language development. Language Science, $1,69-88$.

Tomasello, M. (2003). Origens culturais da aquisição do conhecimento humano. São Paulo: Martins Fontes.

Tomasello, M., Kruger, A. C., \& Ratner, H. H. (1993). Cultural learning. Behavioral and brain sciences, 16, 495-511.

Trevarthen, C. (1979). Communication and cooperation in early infancy: A description of primary intersubjectivity. In M. Bullowa (Ed.), Before speech (pp. 321-347). New York: Cambridge University Press.

Trevarthen, C. (1984). Emotions in infancy: Regulations of contact and relationships with persons. In K. R. Scherer \& P. Ekman (Eds.), Approaches to emotion. New Jersey: LEA. 
Vera Silvia Raad Bussab, Maria Isabel Pedrosa e Ana Maria Almeida Carvalho

Trevarthen, C. (1998). The concept and foundations of infant intersubjectivity. In S. Bråten (Ed.), Intersubjective communication and emotion in early ontogeny (pp. 15-46). Cambridge: Cambridge University Press.

Trivers, R. L. (1971). The evolution of reciprocal altruism. Quarterly Review of Biology, 46(4), 35-57.

Vygotsky, L. S. (1934/1986). Thought and language. Cambridge: MIT Press.

Wallon, H. (1971a). A expressão das emoções e seus fins sociais. In As origens do caráter na criança: os prelúdios do sentimento de personalidade (pp. 89-94). São Paulo: Difusão Européia do Livro. (Trabalho original publicado em 1934)

Wallon, H. (1971b). Sincretismo diferenciado: II. A simpatia. In H. Wallon, As origens do caráter na criança: os prelúdios do sentimento de personalidade (pp. 224-238). São Paulo: Difusão Européia do Livro. (Trabalho original publicado em 1934)

Wallon, H. (1979). Do acto ao pensamento: ensaio de psicologia comparada (2a ed.). Lisboa: Moraes. (Trabalho original publicado em 1942)

Wallon, H. (1986). O papel do outro na consciência do eu. In M. J. G. Werebe \& J. NadelBrulfert (Orgs.), Henri Wallon (Cap. 13, pp. 168-167). São Paulo: Ática. (Coleção Grandes Cientistas Sociais, 52).

Werebe, M. J. G., \& Nadel-Brulfert, J. (1986). Proposições para uma leitura de Wallon: em que aspectos sua obra permanece atual e original? In M. J. G. Werebe \& J. NadelBrulfert (Orgs.), Henri Wallon (pp. 7-36, Coleção Grandes Cientistas Sociais, 52). São Paulo: Ática.

Whiten, A., \& Brown, J. D. (1998). Imitation and the reading of other minds: Perspectives from the study of autism, normal childresn and non-human primates. In S. Bråten (Ed.), Intersubjective communication and emotion in early ontogeny (pp. 260-280). Cambridge: Cambridge University Press.

Zazzo, R. (1978). Do corpo à alma: as respostas de Wallon e de Freud. In H. Wallon, Psicologia e marxismo (Cap. 2, pp. 35-54). Lisboa: Editorial Vega.

Recebido em: 22.05.2006

Aceito em: 7.08.2006 